БАРСУКОВА Татьяна Ивановна - доктор социологических наук, профессор кафедры социологии Института образования и социальных наук Северо-Кавказского федерального университета (355000, Россия, г. Ставрополь, пл. Ленина, 3a; ti94@yаndex.ru)

БАЙРАМКУЛОВА Динара Далхатовна - соискатель кафедры социологии Института образования и социальных наук Северо-Кавказского федерального университета (355000, Россия, г. Ставрополь, пл. Ленина, 3a; by_dinara@list.ru)

\title{
СОЦИАЛЬНОЕ ЗДОРОВЬЕ ДЕВУШЕК- СТУДЕНТОК КАК КАТЕГОРИИ ЖЕНЩИН РАННЕГО РЕПРОДУКТИВНОГО ВОЗРАСТА
}

\begin{abstract}
Аннотация. В статье представлены результаты авторского анализа социального здоровья женщин раннего фертильного возраста. Данная категория включает, наряду с репродуктивными, физические, психические и нравственные составляющие, без оценки которых представление о социальном здоровье женщин данного возраста будет неполным. Объектом интереса эмпирического исследования авторов статьи выступили студентки вузов и колледжей как представительницы категории раннего репродуктивного возраста. Их социальное здоровье было проанализировано с позиции здоровьесберегающих и здоровьеразрушительных практик.
\end{abstract}

Ключевые слова: женщины репродуктивного возраста, социальное здоровье, репродуктивное здоровье населения, ранний репродуктивный возраст, нравственное здоровье

$\mathrm{O}$ храна и улучшение социального здоровья женщин репродуктивного возраста являются важными задачами общегосударственного значения, т.к. социальное здоровье женщин данного возраста можно рассматривать как фактор общенациональной важности. Женщины репродуктивного возраста на протяжении всей истории человечества являлись важнейшей социальнодемографической группой населения. Ее возрастной, количественный и качественный состав служил главным фактором воспроизводства популяции, развитие и сохранение которой является обязательным и необходимым условием существования любого государства. В Стратегии в области репродуктивного здоровья, принятой ВО3, отмечается, что репродуктивное и сексуальное здоровье имеет фундаментальное значение для отдельных лиц, супружеских пар и семей, а также для социально-экономического развития общин и наций ${ }^{1}$.

В России численность женщин репродуктивного возраста как социальной категории имеет стойкую тенденцию к снижению, о чем свидетельствуют статистические данные, прогнозы демографов, что само по себе является негативным фактором, ведущим к депопуляции нации. Кроме того, озабоченность медиков вызывает все снижающийся уровень здоровья женщин фертильного возраста - физического в целом и репродуктивного в частности.

Зависимость состояния здоровья данной категории женщин от социальноэкономических, психологических и моральных факторов, а также от ряда других объективных и субъективных детерминантов с необходимостью демонстрирует потребность в изучении их социального здоровья как интегральной характеристики, в которой фиксируется не только уровень здоровья, но и отношение к нему общества и самих женщин.

Демографическая проблема как одна из глобальных проблем современно-

1 Стратегия в области репродуктивного здоровья в целях ускорения прогресса в направлении достижения международных целей и задач в области развития. Доступ: http://www.who.int/ reproductivehealth/publications/general/RHR_04_8/ru/; http://whqlibdoc.who.int/hq/2004/WHO_ RHR_04.8_rus.pdf (проверено 09.07.2019). 
сти включает в себя такой аспект, как репродуктивное здоровье женского и мужского населения планеты, от уровня которого зависит в большой степени уровень воспроизводства населения, его социальное здоровье. Национальный проект «Демография» ${ }^{1}$ своей целью ставит увеличение ожидаемой продолжительности здоровой жизни до 67 лет; снижение смертности населения старше трудоспособного возраста, увеличение суммарной рождаемости. Также одними из основных целей являются увеличение доли граждан, ведущих здоровый образ жизни, а также увеличение до 55\% доли граждан, систематически занимающихся физической культурой и спортом.

Изучение репродуктивного здоровья населения не дает полного представления о его детерминантах без обращения к теме социального здоровья, в структуре которого репродуктивное здоровье играет существенную роль, наряду с физическим, психическим и нравственным. Обратимся для начала к тем дефинициям социального здоровья, которые представлены в научной литературе, в первую очередь в социологических источниках. Проведя контекстуальный анализ репрезентации данного понятия в обществоведческой литературе, определимся с его семантическим полем. Ключевым понятием в нем выступает категория «социальное здоровье», многоаспектность интерпретации которой с трудом поддается описанию в силу огромного числа дефиниций. В.П. Бабинцев и Л.В. Колпина справедливо отмечают: «Для описания и анализа социальной действительности обществоведческий дискурс все чаще оперирует понятием “социальное здоровье”. Его смысловое поле настолько широко и многозначно, что вмещает в себя огромный спектр не только социальных, но и биологических, психологических, культурных, экономических, политических и других показателей» [Бабинцев, Колпина 2008: 55, 66].

Основной характеристикой, в соответствии с которой выделяется данная категория женщин, является их возраст. К данной группе относят женщин в возрасте, пригодном для деторождения, т.е., от 15 до 45 лет. В этом промежутке времени здоровье женщины в зависимости от факторов, на него влияющих, может меняться и переходить из одного состояния в другое. Таким образом, социальное здоровье женщин репродуктивного возраста - это динамичная характеристика состояния женщин в возрасте от 15 до 45 лет. В соответствии с общепринятой классификацией различают ранний репродуктивный возраст (до 20 лет), оптимальный (20-30 лет) и поздний (старше 30 лет).

Ранний репродуктивный возраст совпадает с периодом вступления в брачные отношения, создания семьи, учебы в школе и вузе, с профессиональным становлением. В это время идет формирование личности, закладываются мировоззренческие установки, в т.ч. и выбор стратегии репродуктивного поведения, которая может быть самосохранительной, саморазрушительной или стратегией равнодушия в отношении своего здоровья.

К числу проблем, с которыми сталкиваются женщины раннего репродуктивного возраста, относятся рождение детей, отношения с семьей супруга, необходимость совмещения семейной жизни с учебой или работой, проблемы с жильем и пр.

В сентябре 2018 г. нами было проведено социологическое исследование «Социальное здоровье женщин репродуктивного возраста, проживающих в Ставропольском крае» в форме анкетного опроса. Респондентами выступили женщины из различных районов Ставропольского края, при этом опрос проводился в городах с разной численностью населения (от 100 до 500 тыс. чел.;

1 https://strategy24.ru/rf/demography/projects/natsional-nyy-proyekt-demografiya (проверено 09.07.2019). 
от 50 до 100 тыс. чел.; до 50 тыс. чел.); в поселках городского типа; в сельских населенных пунктах. Всего в опросе приняли участие 588 чел.

Цель исследования - изучение и комплексная оценка социального здоровья женщин репродуктивного возраста и факторов, его обусловливающих. Вопросы были разбиты на несколько блоков, что позволило выявить оценку женщинами репродуктивного возраста состояния их физического здоровья - репродуктивного и социального в целом. Для реализации задач данной работы мы выбрали те данные, которые касаются социального здоровья девушек-студенток, отнесенных нами к категории раннего репродуктивного возраста.

При подготовке инструментария социологического исследования мы выделили следующие компоненты социального здоровья женщин раннего репродуктивного возраста.

1. Социально-психологическое здоровье женщин репродуктивного возраста, которое характеризуется такими показателями, как самооценка репродуктивного здоровья, социально-коммуникативный компонент, удовлетворенность жизнью, социальное самочувствие, удовлетворенность социальной инфраструктурой среды обитания, взаимоотношения с социальным окружением.

2. Нравственное здоровье женщин репродуктивного возраста, которое характеризуется такими показателями, как соблюдение/несоблюдение социальнонравственных норм представителями данной социально-демографической категории, приверженность определенным ценностям (материнство, семья, детность).

В ходе проведения исследования женщинам было предложено ответить на вопросы, касающиеся их оценки своего физического здоровья в целом, оценки репродуктивного здоровья, социального здоровья в целом. Ответы студенток вузов и техникумов (148 чел., или 25,3\% опрошенных), которых мы отнесли к категории женщин раннего репродуктивного возраста (были выбраны ответы студенток в возрасте от 17 до 20 лет), показали следующее. На вопрос: «Часто ли Вы задумываетесь о состоянии своего здоровья и оценке его состояния?» - преобладали ответы «скорее да» и «скорее нет».

Свое здоровье оценивают как хорошее немногим более $30 \%$ опрошенных, как среднее - 52,6\% девушек, участвовавших в опросе. Вызывает беспокойство тот факт, что плохим и очень плохим в совокупности свое здоровье назвали 5,3\% респондентов. Достаточно благоприятной представляется картина с частотой заболеваний у девушек (см. табл. 1).

Таблица 1

\section{Распределение ответов на вопрос: «Как часто Вы болеете?»}

\begin{tabular}{|l|c|}
\hline \multicolumn{1}{|c|}{ Варианты ответа } & Доля, \% \\
\hline Очень часто, постоянно & 3,7 \\
\hline Часто & 17,9 \\
\hline Редко & 64,3 \\
\hline Практически не болею & 5,6 \\
\hline Затрудняюсь ответить & 8,5 \\
\hline Итого & 100 \\
\hline
\end{tabular}

Редко и почти не болеют в совокупности почти $70 \%$ девушек. Свое здоровье, согласно следующему вопросу, большинство респондентов оценили (по шакале 
от 5 до 1 балла) на «хорошо». При этом 33,8\% оценили его на «удовлетворительно», что является тревожащим симптомом с позиции рассмотрения уровня здоровья женщин данной возрастной группы. Более всего, согласно полученным данным, девушек беспокоит состояние системы органов пищеварения; также отмечены центральная нервная, костно-мышечная система, системы органов кровообращения, дыхания и иммунная система. Репродуктивная система в иерархии систем, беспокоящих респондентов, оказалась на 9-м месте из 12. Следят за своим здоровьем 68\% (ответы «да» и «скорее да»); «скорее нет» ответили $24,1 \%$, и «нет» $-5,1 \%$. Остальные затруднились с ответом. Большинство девушек стараются регулярно проходить медицинское обследование независимо от того, как себя чувствуют, при этом около половины опрошенных лечатся самостоятельно, а 1/10 респондентов практически не обращаются к врачу.

Можно констатировать, что в отношении к своему физическому здоровью студентки, отнесенные нами к женщинам раннего репродуктивного возраста, демонстрируют в своем большинстве здоровьесберегающую стратегию, но достаточно велико число и тех, кто равнодушен к нему.

В сексуальных отношениях состоят около половины опрошенных. Все опрошенные знают, что такое экстракорпоральное оплодотворение. Венерическими болезнями не болел никто из опрошенных; болезнями, передающимися половым путем, согласно опросу, болели 7\%. Выявляя стратегии поведения в отношении здоровья, в т.ч. и репродуктивного, мы выявили следующие данные: 1/4 опрошенных обращаются к гинекологу 1 раз в полгода; немногим более 1/3 1 раз в год. Те, кто не посещает врача, причины объяснили так: «не вижу необходимости» - около 1/3 опрошенных, «не болею» - более половины. Среди вариантов ответа «другое» указаны такие причины, как «нет времени», «лень, безответственность», «страшно». Налицо явно выраженная стратегия равнодушия к своему репродуктивному здоровью.

Чаще всего респонденты обращаются к стоматологу и окулисту. В периоды распространяя ОРВИ, гриппа меры по их профилактике принимают далеко не все респонденты (см. табл. 2).

Таблица 2

Распределение ответов на вопрос: «В периоды распространения ОРВИ, гриппа Вы принимаете меры их профилактики лично для себя?»

\begin{tabular}{|l|c|}
\hline \multicolumn{1}{|c|}{ Варианты ответа } & Доля, \% \\
\hline Да, всегда & 33,7 \\
\hline Да, но не всегда & 50,3 \\
\hline Нет & 14,1 \\
\hline Затрудняюсь ответить & 1,9 \\
\hline Итого & 100 \\
\hline
\end{tabular}

Ряд вопросов мы сформировали в блок, касающийся социального здоровья женщин раннего репродуктивного возраста в целом. Ниже представлены данные об источниках получения респондентами сведений о социальном здоровье. При возможности выбора нескольких вариантов ответов мы получили следующие данные. Основными источниками информации для девушек выступили: мать $(67,5 \%)$, подруги $(56,4 \%)$ и Интернет $(70,3 \%)$. Ответы «телевидение» «газеты» «журналы» «свекровь», «сестра/сестры» набрали незначительный вес. 
Среди ответов «другое» названы «биографии», «монографии заслуженных деятелей искусства, их лекции», «общение со старшим поколением, позитивно отзывающимся о своих семьях», «книги», «медицинская литература», «получение медобразования», «Священное писание».

Более половины опрошенных знают о том, какие требования общество предъявляет к физическому здоровью женщин репродуктивного возраста, 1/5 респондентов имеют об этом представление. Остальные дали ответы: «слышали», «не знаю» или затруднились с ответом. Похожая картина сложилась и с ответами на вопрос о том, какие требования общество предъявляет к психическому и нравственному здоровью женщин репродуктивного возраста.

Девушкам также было предложено оценить по 5-балльной шкале значимость факторов, влияющих на сохранение социального здоровья женщин репродуктивного возраста.

Таблица 3

Распределение ответов на вопрос:

«Что, на Ваш взгляд, является ценностью для сохранения и поддержанания социального здоровья женщин репродуктивного возраста?», \%

\begin{tabular}{|c|c|c|c|c|c|c|c|}
\hline \multirow{2}{*}{ Ценности } & \multicolumn{5}{|c|}{ Баллы } & \multirow{2}{*}{$\begin{array}{c}\text { Затрудняюсь } \\
\text { ответить }\end{array}$} & \multirow{2}{*}{ Итого } \\
\hline & 1 & 2 & 3 & 4 & 5 & & \\
\hline Рациональное питание & 3,9 & 3,2 & 11,2 & 20,2 & 50,2 & 11,2 & 100 \\
\hline Хорошие семейные отношения & 3,2 & 1 & 7 & 15,6 & 61,9 & 11,2 & 100 \\
\hline Регулярные половые связи & 8,8 & 5,8 & 15,5 & 16,2 & 35 & 18,7 & 100 \\
\hline Отсутствие болезней & 4,3 & 1 & 4,8 & 11,4 & 71,4 & 7,1 & 100 \\
\hline $\begin{array}{l}\text { Благоприятная экологическая } \\
\text { обстановка }\end{array}$ & 4,1 & 2,2 & 6,3 & 17,5 & 58,7 & 11,2 & 100 \\
\hline Хорошие жилищные условия & 2,6 & 1 & 9,9 & 25,3 & 47,6 & 13,6 & 100 \\
\hline $\begin{array}{l}\text { Благоприятные отношения в } \\
\text { коллективе }\end{array}$ & 3,7 & 5,8 & 17,2 & 24,8 & 30,6 & 17,9 & 100 \\
\hline Место проживания & 3,1 & 2,4 & 13,1 & 23,6 & 41,3 & 16,5 & 100 \\
\hline Наличие работы & 6,5 & 4,6 & 12,8 & 22,4 & 40,1 & 13,6 & 100 \\
\hline Хорошая зарплата & 3,9 & 2,9 & 8,5 & 19,2 & 52,6 & 12,9 & 100 \\
\hline Хорошее здоровье & 2,6 & 0,3 & 4,1 & 9,4 & 70,6 & 13,1 & 100 \\
\hline Возможность иметь детей & 3,2 & 1 & 4,8 & 9,7 & 63,9 & 17,3 & 100 \\
\hline Возможность обеспечивать детей & 2,2 & 1,2 & 4,8 & 14,6 & 63,6 & 13,6 & 100 \\
\hline Любовь & 3,1 & 2,2 & 6,3 & 12,8 & 58,7 & 17 & 100 \\
\hline Материальная обеспеченность & 2,2 & 1,9 & 6,5 & 21,1 & 56,6 & 11,7 & 100 \\
\hline
\end{tabular}

* Оценка производится по 5-балльной шкале, где 1 балл - не является ценностью, 5 баллов - высшая ценность).

Особый акцент нами был сделан на анализе данных, касающихся поведения девушек, что дало возможность говорить о преобладающей стратегии в отношении своего репродуктивного здоровья. О том, что они имеют пристрастие к табакокурению, заявили более половины девушек, при этом стаж курения составляет в основном от 1 года до 3 лет.

Употребляют спиртные напитки около 1/3 опрошенных, и делают это также 
в основном от 1 года до 3 лет. На вопрос: «Приходилось ли Вам когда-либо употреблять наркотики?» - все девушки ответили отрицательно.

Таким образом, мы можем сделать вывод о преобладании в поведении девушек-студенток стратегии равнодушия к своему репродуктивному здоровью с элементами саморазрушительных практик. Такая картина свидетельствует о необходимости совершенствования мероприятий по разработке и реализации информационно-образовательных программ, направленных на информирование обучающихся о вреде табакокурения, потребления алкоголя, наркотических средств и психотропных веществ, с обязательным акцентом на влиянии данных факторов на репродуктивное здоровье.

Майкл П. Келли и Мэри Баркер в своей статье «Почему так сложно изменить поведение, связанное со здоровьем?» приводят доказательную базу, поясняющую, как автоматические и рефлексивные системы, уже описанные и апробированные в психологии и теории социальной практики как одной из областей социологии, являются особенно важными новыми областями для развития идей об изменении поведения. Именно эти идеи должны лечь в основу политики, стратегии и конкретных программ, направленных на сохранение социального здоровья людей. Важно понимать условия, которые ведут к формированию устойчивых моделей поведения, для того чтобы сочетать психологические представления об автоматических и рефлексивных системах с социологическими представлениями о социальной практике. В научной работе авторы приходят к заключению, что социальный институт здравоохранения не справится с задачей изменения устойчивых моделей поведения, связанных с негативным воздействием на здоровье человека. Необходима системная работа, в т.ч. в области социальной рекламы, средств массовой информации, образования и др., для формирования устойчивых ценностных ориентаций на социальные практики и поведение, сохраняющие здоровье человека [Kelly, Barker 2016].

Совершенно справедлив в отношении полученных нами результатов вывод, подытоживающий исследование представлений о здоровье и здоровьесбережении у студенческой молодежи, проведенное группой ученых под руководством В.И. Филоненко (2018 г.), что у студентов нет потребности в систематической заботе о собственном здоровье [Филоненко и др. 2018: 156].

Вместе с тем нам представляется, что в условиях общества потребления с преобладанием в молодежной среде социальных практик развлечения и потребительства формирование стратегии самосохранительного поведения в отношении ее репродуктивного здоровья весьма затруднительно как для родителей, так и для учебных заведений.

Статья подготовлена к публикации в соответствии $c$ реализацией внутреннего гранта ЮФУ № внгр-07/2017-27.

\section{Список литературы}

Бабинцев В.П., Колпина Л.В. 2008. Проблема формирования категориального аппарата понятия «социальное здоровье». - Научные ведомости Белгородского государственного университета. Сер. Философия. Социология. Право. № 12. T. 5. C. 49-67.

Филоненко В.И., Никулина М.А., Патраков Э.В., Ковтун О.П. 2018. Представления о здоровье и здоровьесбережении у студенческой молодежи. Социс. Социологические исследования. № 7. С. 152-157.

Kelly M.P., Barker M. Why Is Changing Health-Related Behaviour So Difficult? Public Health. 2016. Vol. 136. P. 109-116. 
BARSUKOVA Tatiana Ivanovna, Dr.Sci. (Soc.), Professor of the Chair of Sociology, Institute of Education and Social Sciences, North Caucasus Federal University (3a Lenina Sq, Stavropol, Russia, 355000; ti94@yandex.ru)

BAIRAMKULOVA Dinara Dalkhatovna, applicant at the Chair of Sociology, Institute of Education and Social Sciences, North Caucasus Federal University(3a Lenina Sq, Stavropol, Russia, 355000; by_dinara@list.ru)

\section{SOCIAL HEALTH OF FEMALE STUDENTS AS WOMEN'S EARLY REPRODUCTIVE AGE CATEGORY}

Abstract. The article is devoted to the issue of social health of women of early reproductive age, which includes reproductive, physical, mental and moral components. The authors identify and substantiate the need to study this issue on the base of the downward trend in the number of women of fertile age in Russia and the deterioration of their physical health.

The authors present the results of sociological study "The Social Health of Women of Reproductive Age Living in the Stavropol Territory» (588 female respondents). The purpose of the study is to assess the social health of women of reproductive age and factors responsible for it. The study make it possible to analyze the social health of this category of the population from the standpoint of health-saving and health-damaging practices. The authors draw conclusion about the predominance of the strategy of indifference to their reproductive health with elements of self-destructive practices in the behavior of female students.

Keywords: women of reproductive age, social health, reproductive health of population, early reproductive age, moral health

ДУДИНА Ольга Мухаметшевна - кандидат философских наук, доцент; доцент департамента социологии, истории и философии Финансового университета при Правительстве РФ (125993, Россия, г. Москва, Ленинградский пр-кm, 49; OMDudina@fa.ru)

СКОК Александр Степанович - доктор социологических наук, научный сотрудник Научноисследовательского центра (социологического) Вооруженных сил РФ (123001, Россия, г. Москва, Б. Садовая ул., 14; astmsu@yandex.ru)

\section{СОЦИОЛОГИЧЕСКИЕ МЕТОДИКИ В АНТИКРИЗИСНОМ УПРАВЛЕНИИ ОРГАНИЗАЦИЕЙ}

Аннотация. Статья посвящена возможностям применения социологической методики в оценке руководства организацией. Такие методики могут быть использованы в антикризисном управлении. В статье описывается методика оценки деятельности и деловых качеств руководителей отделов, а также ее возможности для оценки высшего руководства компании. Она включает в себя совокупность социологических методов сбора информации: анализ документов, анкетирование, полуформализованное интервью, социометрическую процедуру, тестирование методами СМИЛ и цветовых выборов Люшера. Авторы указывают, что обеспечение условий полной анонимности во время сбора информации является категорическим требованием методики.

Ключевые слова: социологическая методика, антикризисное управление, уровень неудовлетворенности деятельностью и деловыми качествами руководителя, спектр неудовлетворенности, коэффициент приемлемости/неприемлемости руководителя

Б ыстро развивающееся антикризисное управление предполагает взаимодействие не только с экономической, но и с социологической наукой. Это следует хотя бы из того, что она обладает определенными социальными технологи- 